\title{
Enabling Sociability When Using Virtual Reality Applications: A Design Science Research Approach
}

\author{
Jani Holopainen \\ University of Helsinki \\ Strategic Marketing and \\ Management \\ jani.m.holopainen@helsinki.fi \\ Essi Pöyry \\ University of Helsinki \\ Consumer Society Research \\ Centre \\ essi.poyry@helsinki.fi
}

\author{
Osmo Mattila \\ University of Helsinki \\ Strategic Marketing and \\ Management \\ osmo.mattila@helsinki.fi \\ Tuure Tuunanen \\ University of Jyväskylä \\ Faculty of Information \\ Technology \\ tuure@tuunanen.fi
}

\author{
Petri Parvinen \\ University of Helsinki \\ Strategic Marketing and \\ Management \\ petri.parvinen@helsinki.fi
}

\begin{abstract}
Immersive virtual reality applications aim at providing an all-encompassing spatial experience where a user can feel like being in another world or dimension. The systems are inherently designed for individual use as the devices disconnect the user from the physical environment. However, the applications are seldom used alone. Specifically, when used for sales and marketing, the user often needs help from other people but also benefits from social interaction as a part of the experience. Design research methodology is applied to three iterative development versions of a virtual-reality application. The focus of the evaluation of the artifacts is in the social use emphasizing three sociability factors: shared knowledge, mutual trust and influence. According to the findings, the users prefer personal social interaction as a part of the experience. Thus, the social aspect should be emphasized in the service design.
\end{abstract}

\section{Introduction}

Immersive virtual reality (VR) technology enables multi-sensorial experiences that have potential to provide additional powers for its user through increased perceptual fidelity [1]. The rapid technological advancements have created buzz in the popular media [e.g., 2,3,4] and academic research has also started to increase in volume and breadth. The current VR-related customer experience literature has mainly concentrated on the user's individual interactions with the system for example by studying interactions with virtual objects [5], storylines and narratives [6] and sensory effects including visuals, sounds, movability and haptics $[7,8,9]$.

However, it has been noticed that social factors related to the use context may significantly affect the user experience. It has been found that VR may provide improved social interactions between customers (users), business representatives and fellow customers by generating new encounters [10]. VR also generated positive word-of-mouth within the users' own social networks. It has been found that advertisements using VR technology can create increased engagement between the user and the brand, as well as between different users and bystanders [11]. According to another research, a salesperson assisting the use of a VR application helped customers to appreciate the products the application showcased more than they did without the salesperson - otherwise the focus tended to be on the technology [12]. These notions warrant a deeper investigation of the effects that social interactions have on the way VR technology is being used, and to what extent personal guidance is needed when using VR applications - a key question regarding the scalability of the technology.

In this research, we focus on interactions with a novel technological system in the following social contexts: user as a part of peer-group, user interacting with a service employee in-person and remotely, and user in her own social context. In particular, we focus on three key interaction characteristics or sociability perspectives: shared knowledge, mutual trust and influence [13]. The literature shows a gap of theoretical knowledge of social interactions when using VR applications. Further, many companies, such as those in the natural resource management sector, lack interactions between customers and their front- 
line service employees [14]. Our objective is to create ways of increasing sociability between these two parties with three interaction elements: trust, influence and shared knowledge [13]. Consequently, our research question is the following: How to enable the sociability between customers and front-line service employees with the VR application?

Design science research methodology (DSRM) was used to describe the development process of a VR application consisting of three iteratively developed versions. The application was developed by forest industry company and it aims at digitalizing laborintensive customer service in a use context that is challenged by long physical distances. The evaluation of the development versions focuses on sociability when using the VR-application. The empirical data was collected during each of the iteration rounds and it consists of transcribed video recordings of the users testing the application and transcribed audio recordings of user interviews.

The study makes contributions by demonstrating how individuals' system interaction differs from social system interaction. Secondly, the study demonstrates how system interaction differs when user is being guided in person versus remotely. As suggested by the design science research literature $[15,16]$, the study draws implications for both technology- and management-oriented audiences.

The paper is structured as follows: First we introduce the social interactions theory as a framework to study VR. Second, we present the DSRM including artifact design, -development, -demonstration and -evaluation. The results are presented according to the study framework followed by summary and implications.

\section{Virtual Reality and Social interactions}

Creating trust and influence between information system groups can lead to shared knowledge and have a significant impact on information system performance [13]. Interactions in virtual environments can enable multiple benefits such as illustrative visualizations and scalability of the system [17]. In addition to cognitive benefits such as learning, also social and personal integrative benefits as well as hedonic benefits were recognized. These can further involve customers in innovation and value co-creation processes and affect the customers' attitude towards the firm $[17,18,19,20]$. The existing literature on virtual environment interactions and benefits has concentrated on product support, relationship management, customer commitment and product development [e.g., 17,21,22], while there is no existing information system design literature drawing implications for both technology- and managementoriented audiences.

Trust is "a set of expectations shared by all those in exchange" [23]. Trust can also be created through repeated communications [13] and it can also occur towards an information system. Personal experience, familiarity, affiliation, belonging, transparency, factual signals and heuristic cues may create trust in information systems [24]. While face-to-face interactions are often considered fundamental in creation good-quality relationships and trust $[25,26]$, also computer-mediated trust can evolve to the same level over a time [27]. Similarly, also VR applications induce reciprocal behaviors [10] suggesting potential trust-creation.

Influencing someone is one type of social interaction [13]. Among the influence methods, motivating, extracting and creating common goals [28], is one. In addition, creating cognitive and emotional influences are distinguished as separate persuasion methods [29].

Shared knowledge between the customer, the salesperson and other groups can be created through information systems in the presence of trust and influence [13]. Shared knowledge goes beyond basic informational interaction by deeper forms of interaction [30,31]. Shared knowledge requires common language, that is, words or symbols that each counterpart understands [32].

In this study, we propose that considering the contents, features and use contexts of VR applications, they can offer new kinds of symbols that enhance shared knowledge. Further, they can be used to open new ways for value communication, co-creation and innovations. Next, we present our research methodology, artifact design and its demonstration in the field with three research iterations.

\section{Research Methodology}

We employ the DSRM [16] as our research approach. DSRM has become a popular framework for planning and evaluating service development especially in information systems research $[15,16]$. We build three different versions of the VR application to enable: 1) user's individual interaction with the system, 2) user to act as a part of peer-group, 3) user to interact with a service employee in-person and 4) -remotely 5) user to act in his/her own social context.

In DSRM [16], demonstration phase is a proof-ofconcept that the artefact feasibly works to solve one or more instances of the problem. The demonstration is followed by evaluation, where the purpose is to show utility of the developed artifact [33]. Furthermore, four 
suggested steps for design science research artifact evaluation: 1) explicating the goals, 2) choosing strategies for the evaluation, 3) determining the properties to evaluate, and 4) designing the individual evaluation episodes [33].

In our study, three of researchers were involved in the application development right from the beginning and empirical data was collected during three development iterations of a VR application developed for a natural resource management company. Altogether three different VR artifacts were demonstrated in five different social contexts. The use of the artifacts in these contexts were evaluated based on the sociability perspectives: knowledge sharing, trust creation and influence [13]. The artifacts are described in the next section in more detail.

\subsection{Artifact Design and Development}

During the research process, three iteratively developed versions (artifacts) of the application were used. The objectives for the application development become more exact along with the development iterations but the original idea of improving remote decision making without a need to visit forest estate remained the same. A gaming engine (Unity) was used in the development of all of the artifacts.

The artifact 1 concentrated on the user experience and the objective was to understand the utilities and emotions of using a VR tool to support remote decision making. It consisted of a simple forest model (Figure 1) that was based on a point cloud of a real forest that was scanned by using a stationary terrestrial laser scanner. The precisely scanned area covered a 25 x 25 meters area and it was surrounded by hills. A simplified version of the point cloud and one 360degree photo were imported to the game engine. Based on the point cloud data, an interactive environment was generated by adding basic terrain and trees as interactive assets. The application was used with a VR system (HTC Vive) with two hand-held controllers. The system was connected to a PC and it enabled tracking the physical movement of the user in an area covering $2.5 \times 2.5$ meters. The user was able to teleport herself longer distance in an area, gain money by removing trees simultaneously visualizing how the forest changed. Further, she was able to decide whether she wanted to visit the point cloud and 360degree photo of the real forest. In addition, a bear was set to wander around the forest. It was possible to see a 2D-version of the user's view in VR from a computer screen. This enabled interactions between the user and the bystanders.

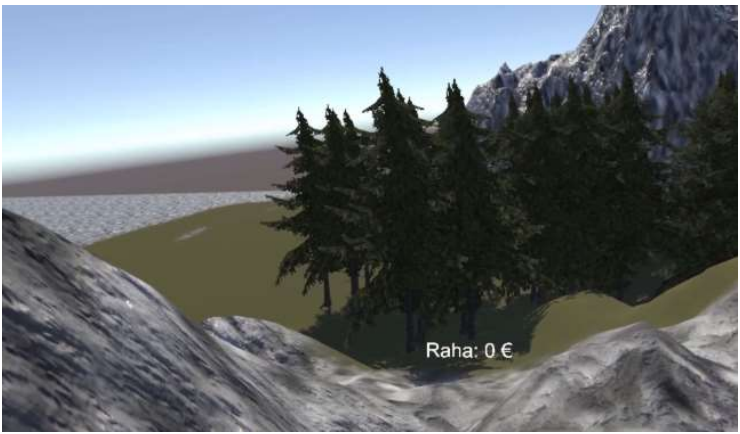

Figure 1. Artifact 1

The artifact 2 aimed to gain scalability by enabling remote interaction between the user and service personnel. A forest estate covering 10 hectares was captured by using a portable terrestrial laser scanner and 360-degree photographs. In addition, open access terrain data was used to support the production of the interactive forest environment. Otherwise, it was created by following the production process of the artifact 1 . Compared to the previous versions, visual quality of the application was improved significantly. The artifact 2 included a larger and more detailed collection of tree assets. In addition, small details such as rocks, undergrowth and dead branches were added to make the experience more realistic. Improved usability enabled the user to gain more detailed information about the forest and single trees (Figure 2). By using a map, the user was able to visit tree areas including different types of forests. In addition to removing single trees, the user was able to make decisions about areal forest management operations, such as clear cutting and thinning. The possibility to see the point cloud was removed along with the bear. The devices to use the system were similar to the devices in the artifact 1 (HTC Vive connected to a PC). In addition to the possibility for a bystander to see the 2D-version of the view in VR, the same view was shared via Skype allowing discussion between the user and the service person remotely. In remote interaction, the service person was also able to see the user via a web-camera. This helped in guiding to use the devices.

The objective of the artifact 3 was to allow the use of the system in more versatile social situations such as at home or as a part of normal customer meeting. This objective was fulfilled by developing a version for mobile VR devices (Samsung Gear VR with one hand-held controller). The artifact 3 contained improved graphics (Figure 3) and a simplified user interface that was optimized for mobile use one controller. Moving was only possible by teleporting to pre-selected slots in the forest. 


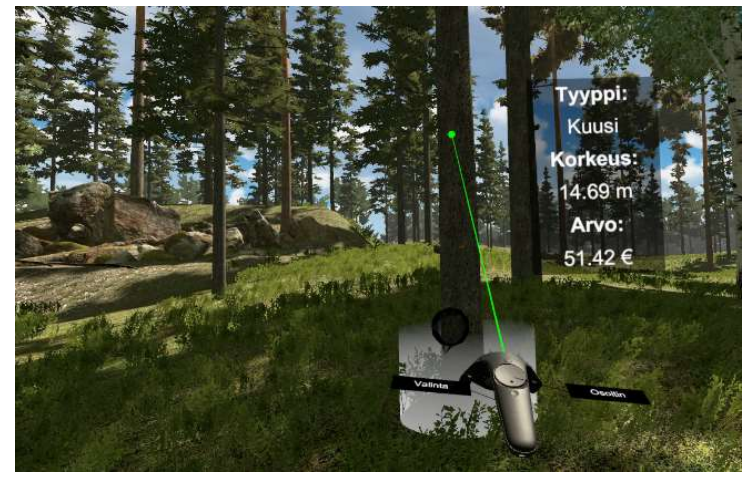

Figure 2. Artifact 2

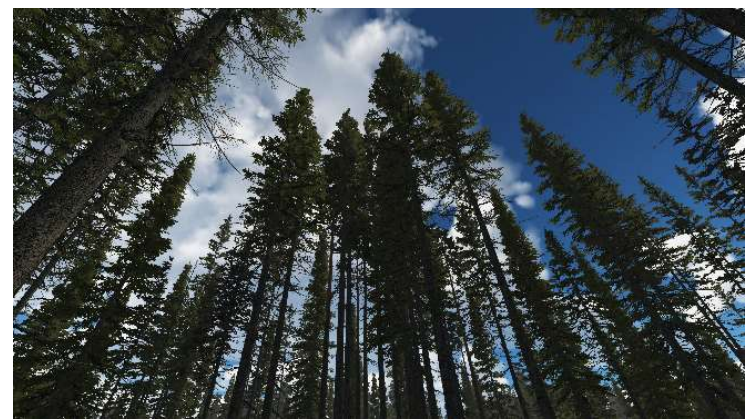

Figure 3. Artifact 3

\subsection{Artifact Demonstration}

The artifact 1 was demonstrated in two social situations: 1) user's individual interaction with the system, and 2) user to act as a part of peer-group (Figure 4). Because the users were generally not familiar with the system, there was a researcher helping them to attach the headsets, to show the controls and to briefly introduce the topic if the user was not familiar with it.

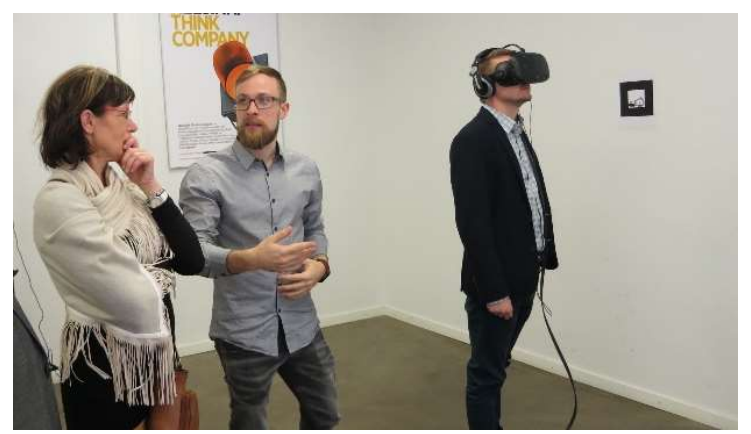

Figure 4. Demonstration of artifact 1 - user as a part of a peer-group

A group consisted of 50 invited users who were mainly managers of industrial companies and interested in utilizing VR in their business. Half of them tested the artifact alone without peer attending the use. Half of the users tested the artifact as a part of a group meaning that there was at least one peer watching and commenting the use. In peer-group use, bystanders were standing next to the user and were able to see a 2D-version of the view in VR from a computer screen.

Artifact 2 of the VR application focused on comparing two different social situations: use with a service employee in person and remotely (Figure 5). The tests were organized by the company and 64 invited users tested the application. 37 of the users tested the application with the personal help of a service employee and 27 with the same employee helping remotely via Skype. Majority of the users were forest owners and customers of the firm. Therefore, the demonstration of artifact 2 was closer to an authentic use situation compared to artifact 2. Further, the demonstration situation was more controlled.

The artifact 3 aimed at allowing the use of VR application in more versatile social situations. A version optimized for mobile use was introduced to 15 customers of the industrial company as a part of normal customer meetings. A researcher participated the meetings by observing the use of the artifact and by interviewing the customers right after the meeting and two weeks afterwards by a phone.

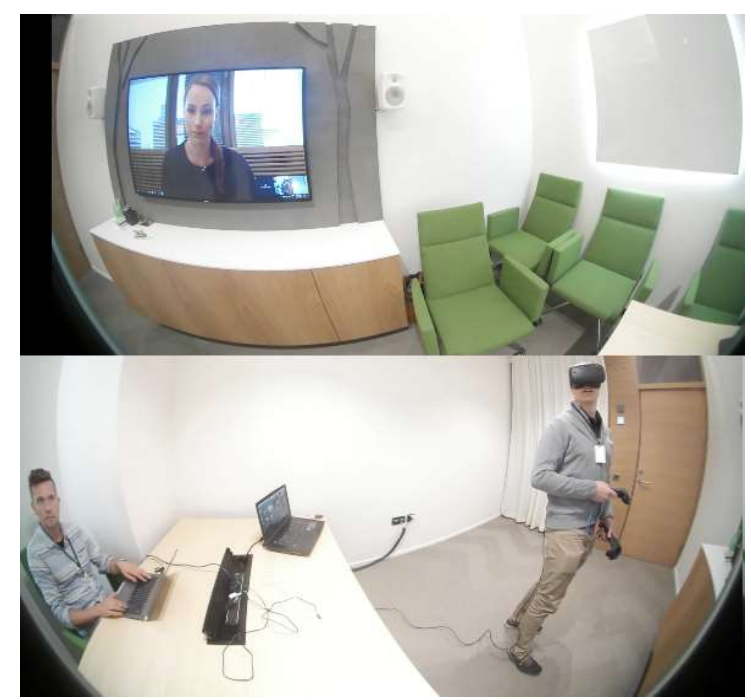

Figure 5. Demonstration of the artifact 2 user interacting with a service employee remotely while a researcher observing

\subsection{Artifact Evaluation}

We follow the four steps for artifact evaluation [33]. The problem identification leading to the research objective and -question explicate the goals for the evaluation. In terms of evaluation strategy, we choose "Human Risk \& Effectiveness" -strategy as our 
main interest is in various social situations and as in our case, it is possible to conduct the evaluation with real users in their real use-contexts. The applied theories named social interactions [13] determine the properties for the evaluation. The individual evaluation episodes in five different social situations between 2016 and 2018 resulted altogether 129 tested users. In the following, the individual evaluation episodes and data collection for the artifacts 1-3 are introduced.

For the artifact 1, the data included open-ended interview questions [34] that were recorded on audio and observations during the use [35] that were recorded on video including both user's comments during the use and how they acted in the physical surroundings, including used dynamics and motions [36]. The material was transcribed resulting in 96 pages of observation notes and transcribed interviews.

For the artifact 2, both qualitative and quantitative data was collected using questionnaires, interviews and observations to learn about customer experience, customer learning, brand, behavioral intentions and background information. The questionnaire included questions measured on a 5-point Likert-type scale and structured interview questions. The users were simultaneously observed as avatars in a virtual space and as real persons in the physical space [37]. Observations also included the users' comments during the experience. Both use tests and interviews were recorded and transcribed resulting in 140 pages of observation notes and transcribed interviews.

The artifact 3 was evaluated in 2018 with an ethnographic approach to design [38] trying to deeply understand how the users utilize the application in their own social context. The VR application was introduced before the customer meeting and it was applied during the customer meeting. These meetings were observed, and all involved parties were interviewed. Two weeks after the customer meeting the customers were interviewed on their experiences in how they would utilize the system in their own social context. The user interviews were transcribed resulting 45 pages of text.

\section{Findings}

We report the findings on the sociability between users and front-line service employees when using a VR application following the research framework [13]. According to the findings, VR applications can be used to open new ways for value communication, co-creation and innovations, and users prefer personal social interaction as a part of the experience.

\subsection{Knowledge sharing}

A service employee being present in the demonstrations guided the users to use the applications in a desired manner, which also helped the employee to better understand usability problems. It also turned out that the more sales-oriented service employees with a basic understanding of the technological features of the application could transmit the required usability information back to the company and application developers by simultaneously concentrating on the customer experience and addedvalue. Therefore, technical personnel were not required to be present in the demonstrations.

The VR headsets exemplified a unique service situation by blocking visual and audio connections to the real world, which made the users dependent on the service personnel (making sure they did not stumble on a cable or collide with a wall). This unusual social situation made it easy to start a conversation. The users often needed help when using the devices and with the most of their functionalities, and the guided use naturally entailed making a physical connection with the service employee.

The application, especially its first development version, seemed like a computer game. Therefore, knowing that the surroundings were based on a real world seemed to interest the users. That was a feature that was developed during the iterations by for example adding a map of the area. "I started immediately thinking what this valley is. Every now and them, I visit Nuuksio (a national park) picking mushrooms." (Peer-group use, artifact 1).

These kinds of comments by users led to a fruitful conversation with the service employee and bystanders. The key for these conversations was that the user could attach the VR experience to a real-life context and share thoughts based on real-life experiences. This contributed to better understanding of user personality, value base and expectations as well as building familiarity and trust between the user and service employee. However, with the remote service employee in the artifact 2 , the users were a bit more anxious and reserved, when these kinds of casual conversations did not occur.

Even though point cloud was considered an interesting and illustrative element connecting the user to the real place, it was removed from the next development versions as it including 360-degree photos of the forest was considered to be enough to connect the user with real-life and thus new conversations and insights could not be extracted.

Service information embedded in the application was considered focal to reach the objectives of the application and it was increased along with the 
application development iterations. The artifact 2 included more information about single trees and the forest site. By increasing the number of informative elements, it was easier for the users to focus on the content that was guiding them towards the main objectives of the application. However, information and requirements for details varied a lot between the users. Some of the users who clearly regarded themselves as professional foresters criticized "vague" presentation of information. In other words, using special terminology and symbols correctly was important especially when using the system with a service employee in the artifact 2: "How about seeing how much one has cubic meters? One could see the (cubic) price of the log in that area, the price of birches, that would be way more interesting than the price of a single tree." (Service employee in person, artifact 2). "Focal for us is to see the length and the diameter breast height, that is at the height of 1.3 meters, when estimating single tree." (Service employee remotely, artifact 2). "The ability to see even the size and the price of a single tree and to compare the revenues from thinning and clear cutting. And to see how the forest looks afterwards." (Service employee in person, artifact 2).

Accurate and useful information was fundamental for value communication and, if this was not adjusted to the user knowledge level, user innovation and value co-creation processes could not proceed. These kinds of relevant value communications occurred both in person and remotely.

\subsection{Trust creation}

The peer-group use of the artifact 1 helped users to trust the system. The atmosphere in the demonstration of the artifact 1 was relaxed and the users were able to observe how others used the system before trying out by themselves. This made the social use context safe for those who wanted to observe the use before testing the application by themselves.

In addition, surprising content elements encouraged people to fool around with the system. This lowered the threshold and encouraged people to test the application. Playful elements and relaxed atmosphere also encouraged people to try things that were not obvious: "Hehehe, (teleported to a tree), I was able to climb up a tree!" (Peer-group use, artifact 1).

The fact that the surroundings in VR were based on a real-life context made the experience more credible. However, many users also required more realism: "Let's say that when this is more realistic (...) you would be certain and could rely on that the fact that the forest is like it seems. For remote owners who don't know their forests too well - it would be important." (Service employee remotely, artifact 2).

Consciousness of visiting a real forest site was elevated by including 360-degree photos of the forest site in the artifact 2 and even higher resolution photos in the artifact 3. Photos demonstrated that the application represented a real forest rather than just a generated one. Similarly, users asked whether the value of the trees was based on real-time market prices and tried to evaluate their accuracy: "Price is what finally makes the difference. Here you could see some kind of an estimation of it. Or you actually got it very easily, that was maybe the most valuable part of this experience." (Service employee in person, artifact 2).

There were some results indicating differences in trust between remote and present expert tutoring. For example, over a half of the users tutored in-person gave contact information of their friend or family member which was considerably more than among those who were guided remotely.

\subsection{Influence}

Playfulness was significantly increased in a group use and the users invented new ways of utilizing the features of the application. For instance, when a group of people knowing each other were testing the artifact 1 , one of them started to removing trees with a laser beam as quickly as possible and encouraged others to behave in the same way. This resulted in a competition of trying to remove all the trees as quickly as possible which was originally not planned as a part of the application: "Where is the forest? I've destroyed all the trees! You guys want to come and give it a try?!" (Group use, artifact 1).

Playfulness improved the motivation, and this was emphasized in the peer-group situations. In addition, inventing new features engaged the user, but also motivated peers in the group to test those features.

Peer-group bystanders commented the view e.g. by encouraging the user to ride a bear. Users were also willingness to share the experience during the use and right after removing the headset by commenting the events in VR. However, the system was not designed for sharing the experience in any other ways besides enabling bystanders to watch the use and view in VR from a computer screen. Some of the users realized only after removing the headset that the bystanders were able to see the view in VR from the computer screen. Before realizing that they were actively commenting on what they were seeing in VR to the bystanders.

Overall, dramatic or unusual experiences (such as confronting a bear or high mountains) resulted in a high willingness to share the experience with everyone 
in the room even while still using the VR device. In terms of drama, especially for first-time users, the turning point was clearly when the headset was put on. Regardless of the users' initial attitude, however, the reactions were positive, as shown in their eagerness to share the experience with the service employee. With the artifact 1 for example, this was the point when users started to innovate their own ideas about using the devices and what might be interesting or beneficial as cases. The experience was strong and difficult to imagine beforehand, even if cues had been given a priori e.g. via seeing the use of peers. According to the observations, the presence of fellow users affected a given person's user experience surprisingly little: the surprise factor remained the same. In terms of experience, there seemed to be no difference from the more social service encounters. However, data on the interactions in terms of the discussions between peergroup bystanders not were collected.

The surprise element always made the user to share the experience with the service employee (in twosome situations) and with the bystanders (in peer-group situations). This was also the case with the users who were more silent and introverted during the overall experience. Also, these users reacted even during the remote tutoring: "Wow, all trees are gone, so sad!" (Service employee remotely, artifact 2).

These kinds of situations gave the service employee a chance to grasp the user personality, value base and expectations to proceed with the value communications. For example, the reaction of the service employee on the previous quote was: "Well fortunately this is only a virtual forest and in your own forest we can make much lighter treatments." (Service employee remotely, artifact 2).

Along with the development iterations, the application focus moved from testing single functions and features, even the funny ones, towards supporting the user decision-making. Along with this, the features of the application and the usability design became easier: for example, the comparison of the management outcomes and removing trees. This reduced the need for technical guidance and improved the focus on the main objectives of the application.

According to preliminary results on the artifact 3 , in the customer meetings between the customer and service employee the application content was referred in discussions. This occurred when abstract issues, such as different forest harvest models, were mentioned. The references were made by both customers and service employee nonverbally by pointing the VR gears or/and mentioning "such as in the VR application". In the interviews it occurred that these references worked as risk mitigation factors in terms of understanding the consequences of decisions.
Similarity in the customer's own social context, such as with the family members, the customers used the application to ensure that all the members concerning the decision would be heard and the decision making would be democratic.

\section{Discussion}

\subsection{Theoretical implications}

According to our results, accurate and useful information and content was fundamental for the value communications. Also, visualization and explaining abstract issues in VR was found to be beneficial. However, if all this was not adjusted to the customer knowledge level, the customer innovation and value co-creation processes could not proceed. These kinds of relevant value communications occurred both in person and remotely. These findings confirm previous research highlighting personal experience, familiarity, affiliation and belonging, transparency, factual signals as well as heuristic cues as factors creating trust and shared knowledge in information systems [24].

In addition to those findings, dramatic or unusual experiences as well as playfulness resulted in a high willingness to share the experience and initiated casual conversations and further to deeper value communications. This effect was weaker with the remote use contexts. All in all, in person use contexts improved trust compared to remote tutoring.

Playfulness also seemingly improved the motivation, and this was emphasized in the peer-group situations, where the bystanders encouraged to play, compete and test new features. However, accurate and useful information and features supporting the customer decision-making required reducing technical guidance, which was in our research case done at the cost of also reducing playfulness. In addition, inventing new features engaged the user, but also motivated peers in the group to test those features.

The main findings related to sociability in VR and related implications to scalability can be presented as follows.

The fun factor. Users' willingness to share fun experiences makes VR a good content for group events. Using VR as a part of an event helps in sharing the experience, even with the applications that are originally designed only for individual use. It is also easy to share the group experiences in more scalable medias by sharing photos and videos of the usage. However, only new and noteworthy experiences are suitable for these purposes.

The group factor. Users and bystanders tend to easily create a group where one is using the devices and others attend by proposing what to do in the virtual 
environment. The setup also attracts groups to stop by and try. This can be used in cases when various users are needed to discuss about large or complex entities. However, hosting of group use events requires active organizers, a resource that is required to enable the experiences also for the more passive participators. The current requirement for participation of multiple users is factor that currently hinders the scalability of many VR services. Considering the way that current VR systems are designed for individual use purposes only, it is surprising how important the social aspect seems to be for the experience - whether it is about using a system in a group or sharing the experience with others. However, a polished design of the total customer experience including the social aspects is not yet industry standard in VR.

Curator-user interaction and dialogue. In majority of the use cases, the use of VR currently requires help of a service personnel. In many cases, this seemed to make users devoted to return the favor by discussing with the service personnel or putting effort in trying to create ideas how to improve the experience. Users were also willing to discuss while wearing the headsets. From the social point of view, if the design does not allow any kind of social interaction, all the potential the users have to discuss and share the ideas is wasted. Instead of trying to automate the use of the systems, the focus should be put on generating value from the social factors that are currently a natural part of design of a successful interaction. However, scalability potential of the value generated from the social features of VR is yet to come. Along with the multiplayer features that are becoming a more natural part of the VR experience designs, interaction with others can be implemented naturally also remotely.

Increased time spent with customer. Especially in sales, VR provides a good excuse for increasing customer engagement and spend time with customers. From a service design point of view, a focal question is how to organize the time efficiently. Companies can also help their customers to continue value creation after the meeting by e.g. designing ways to easily share the experience, that is - at the current state of the technology development - an undervalued concept.

\subsection{Limitations and future research}

This paper is limited to analyzing a design process of only one application. Due to the iterative application development process, the social interaction was not the only factor that was changed, but also the system development features such usability, user-interface, graphics, instructions etc. were also develop between the design artifacts.
Further, the application was developed for a specific purpose in the context of forestry. Therefore, some of the features of the application may be limited to the studied use case only.

Further, the research was conducted in the country of origin of the application, which may influence the behavior of the users participating the research. Because of the novelty of the technology, also the social settings in which the application was studied were new to many. The research setups for testing the artifacts varied from public pop-up events to more controlled laboratory experiments. Similarly, this caused diversity in the research population varying from general managers and business practitioners to the more focused group of forest-owners as existing customers and potential end-users of the service. Therefore, the results could be different when both the technology as well as the way it is utilized socially are institutionalized among the end-user or customer groups.

Finally, measuring the interaction elements including trust, influence and shared knowledge in the sociological research context set the typical limitations of measurements in the social sciences [39].

Nevertheless, the results underline the significance of social factors in designing any new digital services that challenge traditional social interaction. They also point out the need to further study the linkages between sociability and scalability of emerging digital services, for example, with more controlled experiments.

\section{References}

[1] Gigante, M.A., "Virtual Reality: Definitions, History and Applications", Virtual Reality Systems, 1993, pp. 3-14.

[2] Forbes, "How Virtual Reality Will Impact Businesses In The Next Five Years", 2016, available: https://www.forbes.com/sites/forbestechcouncil/2016/07/22 /how-virtual-reality-will-impact-businesses-in-the-nextfive-years/\#5c3adbcc2607

[3] Shuster, B., "Could Virtual Reality Revitalize the Economy?", Wired, 2014, available: https://www.wired.com/insights/2014/10/virtual-realityeconomy/

[4] Waugh (2017)., "Which Industries Could Benefit from Virtual Reality?", The Telegraph, available: https://www.telegraph.co.uk/connect/smallbusiness/tech/pc-world/benefits-of-virtual-reality/

[5] Katicic, J. Häfner, P. and Ovtcharova, J., "Methodology for Emotional Assessment of Product Design by Customers 
in Virtual Reality", Presence: Teleoperators and Virtual Environments. 24 (1), 2015, pp. 62-73.

[6] Alaraj, A., Charbel, F.T., Birk, D., Tobin, M., Luciano, C., Banerjee, P.P., ... and Roitberg, B., "Role of Cranial and Spinal Virtual and Augmented Reality Simulation Using Immersive Touch Modules in Neurosurgical Training", Neurosurgery, 72, 2013.

[7] Schaller, A., Biedenkapp, T., Keil, J., Fellner, D.W., and Kuijper, A., "Immersive Interaction Paradigms for Controlling Virtual Worlds by Customer Devices Exemplified in a Virtual Planetarium", in International Conference on Universal Access in Human-Computer Interaction, 2015, pp. 74-86, Springer, Cham.

[8] Velandia, D., Uribe-Quevedo, A., and Perez-Gutierrez, B., "Human Eye Haptics-Based Multimedia", Studies in Health Technology and Informatics, 196, 2014, pp. 449451.

[9] Feng, M., Dey, A., and Lindeman, R.W., "An Initial Exploration of a Multi-Sensory Design Space: Tactile Support for Walking in Immersive Virtual Environments", 3D User Interfaces IEEE Symposium, 2016.

[10] Holopainen, J. Mattila, O. Parvinen, P. Pöyry, E., and Seppälä, K., "Employing Mixed Reality Applications: Customer Experience Perspective", in Proceedings of the 51st Hawaii International Conference on System Sciences, 2018, pp. 1168-1176.

[11] Scholz, J., and Smith, A.N., "Augmented Reality: Designing Immersive Experiences that Maximize Consumer Engagement", Business Horizons, 59 (2), 2016, pp. 149161 .

[12] Javornik, A., “'It's an Illusion, But It Looks Real!' Consumer Affective, Cognitive and Behavioural Responses to Augmented Reality Applications", Journal of Marketing Management, 32 (9-10), 2016, pp. 987-1011.

[13] Nelson, K. M., and Cooprider, J. G., "The Contribution of Shared Knowledge to IS Group Performance", MIS Quarterly, 20 (4), 1996, pp. 409-429.

[14] Häyrinen, L., Mattila, O., Berghäll, S., Toppinen, A., "Forest Owners' Socio-Demographic Characteristics as Predictors of Customer Value: Evidence from Finland", Small-Scale Forestry 14, 2015, pp. 19-37.

[15] Hevner, A.R., March, S.T. Park, J., and Ram, S., "Design Science in Information Systems Research", MIS Quarterly, 28 (1), 2004, pp. 75-105.

[16] Peffers, K., Tuunanen, T., Rothenberger, M., and Chatterjee, S., "A Design Science Research Methodology for Information Systems Research”, Journal of Management Information Systems, 24 (3), 2007, pp. 45-78.

[17] Nambisan, S. and Robert A.B., "Interactions in Virtual Customer Environments: Implications for Product Support and Customer Relationship Management", Journal of Interactive Marketing, 21 (2), 2007, pp. 42-62.

[18] Prahalad, C. K., and Ramaswamy, V., "Co-Creating Unique Value with Customers", Strategy \& Leadership, 32 (3), 2004, pp. 4-9.

[19] Vargo, S.L. and Lusch, R.F., "Evolving to a New Dominant Logic for Marketing", Journal of Marketing, 68 (1), 2004, pp. 1-17.

[20] Vargo, S. and Lusch, R., "Service-Dominant Logic: Continuing the Evolution", Journal of the Academy of Marketing Science, 36 (1), 2008, pp. 1-10.

[21] Gupta, S. and Kim, H.W., "Developing the Commitment to Virtual Community: The Balanced Effects of Cognition and Affect", Information Resources Management Journal, 20 (1), 2007.

[22] Nambisan, S., "Designing Virtual Customer Environments for New Product Development: Toward a Theory", Academy of Management Review, 27 (3), 2002, pp. 392-413.

[23] Zucker, L., "Production of Trust: Institutional Sources of Economic Structure, 1840-1920", in Research in Organizational Behavior, Staw, B.M. and Cumming, L.L. (Eds.), 1986, pp. 53-111.

[24] Einwiller, S., Geissler, U., and Will, M., "Engendering Trust in Internet Businesses Using Elements of Corporate Branding", in Proceedings of America Conference of Information System, 2000.

[25] Jap, S.D., Manolis, C., and Weitz, B.A., "Relationship Quality and Buyer-Seller Interactions in Channels of Distribution", Journal of Business Research, 46 (3), 1999, pp. 303-313.

[26] Wilson, D. T., “An Integrated Model of Buyer-Seller Relationships", Journal of the Academy of Marketing Science, 23 (4), 1995, pp. 335-345.

[27] Wilson, J.M., Straus, S.G., and McEvily, B., "All in Due Time: The Development of Trust in ComputerMediated and Face-to-Face Teams", Organizational Behavior and Human Decision Processes, 99 (1), 2006, pp. $16-33$. 
[28] Sherif, M., "The Self and Reference Groups: Meeting Ground of Individual and Group Approaches", Annals of the New York Academy of Sciences, 96 (1), 1962, pp. 797-813.

[29] Bush, G., Luu, P., and Posner, M.I., "Cognitive and Emotional Influences in Anterior Cingulate Cortex", Trends in Cognitive Sciences, 4 (6), 2000, pp. 215-222.

[30] Keen, P.G.W., "Relationship of Senior Management and the IS Organization", in Elam, J.J., Ginzberg, M.J., Keen, P.G.W. and Zmud, R.W. (Eds.), Transforming the IS Organization, 1988, ICIT Press, Washington.

[31] Swanson, E.B., "Management Information Systems: Appreciation and Involvement", Management Science, 21 (2), 1974, pp. 178-188.

[32] Zeleny, M., "Knowledge as a New Form of Capital: Part 1. Division and Reintegration of Knowledge", Human Systems Management, 8 (1), 1989, pp. 45-58.

[33] Venable, J., Pries-Heje, J., and Baskerville, R., "FEDS: A Framework for Evaluation in Design Science Research", European Journal of Information Systems, 25 (1), 2016, pp. 77-89.

[34] Babbie, E. "The Practice of Social Research", 1989, Wadsworth Publishing company, California, USA.

[35] Mackellar, J. "Participant Observation at Events: Theory, Practice and Potential", International Journal of Event and Festival Management, 4 (1), 2013, pp. 56-65.

[36] Robson, K., Plangger, K., Kietzmann, J. H., McCarthy, I., \& Pitt, L. (2015). Is it all a game? Understanding the principles of gamification. Business Horizons, 58(4), 411420 .

[37] Biocca, F., "The Cyborg's Dilemma: Progressive Embodiment in Virtual Environments", Journal of Computer-Mediated Communication, 3(2), 1997.

[38] Bødker, K. Kensing, F., Simonsen, J. (2010). Participatory Design in Information Systems Development. Reframing Humans in Information Systems Development pp 115-134.

[39] Macdonald, R., "The uses and misuses of data and models. The mathematization of the human sciences", British Journal of Mathematical \& Statistical Psychology 52, 1999, pp. 137. 